\title{
Using of Microbial Fertilizer as Biostimulant Alleviates Damage from Drought Stress in Guar (Cyamopsis tetragonoloba (L.) Taub.) Seedlings
}

\author{
Alpaslan Kusvuran* and Sebnem Kusvuran \\ ${ }^{1}$ Cankiri Karatekin University Kizilirmak Vocational High School, 18100, Cankırı, Turkey, \\ akusvuran@gmail.com; skusvuran@gmail.com
}

Keywords: Antioxidative enzyme activity, green algae, oxidative stress, SOD, water stress

\begin{abstract}
Drought is a significant environmental stress that limits plant growth and yield. In this study, an investigation of guar, grown under different drought level conditions [(S0: 100\% of field capacity), S1 (depletion of $75 \%$ the available water holding capacity), S2 (depletion of $50 \%$ the available water holding capacity), S3 (depletion of 25\% the available water holding capacity), S4 (no applied irrigation water)] with regards to the impact of Chlorella vulgaris based microbial fertilizer on physiological, morphological, and enzymatic activity was performed. Microbial fertilizer applications significantly increased shoot length, fresh and dry weight of the shoot and root, and leaf number and area of guar plants compared to the only drought stress treatments. In addition, following the above-mentioned procedures, there were significant increases in the relative water content, total phenolic and flavonoid contents, superoxide dismutase (SOD), catalase (CAT), ascorbate peroxidase (APX), and glutation reductase (GR) activity. However, the malondialdehyde (MDA) content were significantly decreased. Hence, the results support the administration of a foliar application to the microbial fertilizer containing microalgae in order to increase the guar plant's defense system, enabling it to tolerate the negative effects resulting from drought stress.
\end{abstract}

\section{Introduction}

Worldwide, crop loss is mainly the result of abiotic stressors like cold, drought, heat, nutrient deficiency, oxidative stress, and salinity, which reduce both the average quality and yields [1]. Drought is a major adverse factor affecting the growth of plants and crop production. Drought stress caused challenges such as biochemical, molecular, morphological, and physiological responses [1, 2]. Roughly, one-third of the Earth comprises arid and semiarid land mass, and occasionally, unpredicted droughts occur on the majority of the other land regions [3]. During drought, multiple strategies are developed by plants in response to stress, comprising numerous adjustments like down- or up-regulation of specific genes, a temporary abscisic acid (ABA) level increase, the accumulation of protective enzymes and compatible solutes, and an increase in antioxidant levels and restricted energy-consuming pathways [4]. Within such strategies, significant indicators of a tolerance to drought include osmotic adjustments and antioxidant capacity. Drought is widelyknown to induce oxidative stress, which results in the reduction of various reactive oxygen species (ROS), such as hydrogen peroxide $\left(\mathrm{H}_{2} \mathrm{O}_{2}\right)$, hydroxyl radicals $(\mathrm{HO} \bullet)$, singlet oxygen $\left({ }_{1} \mathrm{O} 2\right)$, and superoxide $\left(\mathrm{O}_{2}^{-}\right)$[5]. As a result, some antioxidant systems have been developed by plants with the aim of scavenging deadly compounds, such as ascorbate peroxidase (APX), catalase (CAT), glutathione reductase (GR), peroxidase (POD), superoxide dismutase (SOD), and monodehydroascorbate reductase [6].

A bio-fertilizer is simply a substance that contains living microorganisms which when applied to the soil, a seed or plant surface colonizes the rhizosphere and promotes growth by increasing the supply or availability of nutrients to the host plant [7]. According to Ju et al. [8] before now, the term bio-fertilizer was used to include organic fertilizer. However, technically, there is a big difference among them. Researchers in an attempt to distinguish between bio-fertilizer and organic fertilizer said "bio-fertilizers are microbial inoculants consisting of living cells of microorganisms like bacteria, algae, fungi, alone or a combination which may help in increasing crop productivity. 
Microbial biofertilizers play a pivotal role in sustainable agriculture. The main role of microbial fertilizer is to help plant uptake nutrient elements and produce various physiological active materials, which enhance plant tolerance to stress, improve qualities of farm products, and to reduce the application of chemical fertilizers [9].

The microalgae are a biofuel that is superior and photosynthetic, as well as the world's largest oxygen-producing organisms, which are crucial for planetary functions and sustainability of the ecosystem. They may potentially be an alternative that is sustainable for enhancing and protecting agricultural crops. Following the application microalgae products, plants have been reported to have had different responses, such as robust growth, increased yield, improved nutrient uptake, and increased biotic and abiotic stresses resistance (fungal infections, pest attacks, and frost), increased quality, and fruit with a longer shelf life [10-12]. Moreover, microalga polysaccharides have been reported as having a good ability to improve plant growth, which means they may potentially be used as biostimulants. Algae are comprised of active compounds, like organic and free amino acids, enzymes, and phytohormones, as well as bioactive secondary metabolites, vitamins, and vitamin precursors [10-13] essential nutrients and plant growth regulators like auxins and cytokinins [12]. Approximately 40,000 microalgae species have been categorized thus far, and among those, Chlorella vulgaris has drawn the attention of scientists due to its high levels of protein, and biomass totaling more than $55 \%$ dry weight (DW). The high concentration of protein, lipids $(5-40 \% \mathrm{DW})$, and carbohydrates (15-55\% DW) also allows it to be used as animal feed, in human nutrition and cosmetics, as well as in biofertilizers [14].

Guar (Cyamopsis tetragonoloba (L.) Taub.) (Syn. C. psoraliodes), a drought-resistant leguminous crop that grows on sandy, arid and semi-arid soil, is an annual herb that is tall, bushy, hardy, and has a deep-rooted system [6]. However, water stress during the active crop growth stages results into cessation of growth as it influences the photosynthesis and other physiological processes and or death by desiccation [15]. Mac et al. [16] indicated that drought stress occurring at different crop developmental stages, in arid and semi-arid areas could potentially limits plant growth and productivity more than any other abiotic stress. According to Vyas et al. [17], water stress during the pod formation and vegetative stages negatively affected various plant enzyme activities, growth, seed yield, and photosynthesis.

Though several researchers reported the effects of Chlorella vulgaris on plants growth and yield only limited studies were carried on drought tolerance in guar. Hence the objectives herein was investigated the effect that Chlorella vulgaris based microbial fertilizer has on plant growth and the biochemical and physiological responses of guar seedlings under different drought levels; in addition determined the relationship between of microbial fertilizer application and improve drought tolerance.

\section{Material and Methods}

Plants were grown in plastic pots $(12 \mathrm{~L})$ containing a peat:perlite $(2: 1)$ ration in a greenhouse (temperature: $26 \pm 2^{\circ} \mathrm{C}$ and $18 \pm 2{ }^{\circ} \mathrm{C}$ were the day and night temperatures \pm 2 and relative humidity: $65 \% \pm 5$ ). Until 40 days of after sowing (DAS) seedlings were irrigated nutrition solution used was as follows Dasgan and Koc [18]. In the experiment, the pot weight was taken into account when determining the amount of irrigation water. For this purpose pots were weighed daily. All pots were brought to field capacity before the implementation of experimental traits.

As microbial fertilizer containing microalgae (Chlorella vulgaris) was used liquid organic commercial product (Natural Bioplasma ${ }^{\circledR}$, Denge Agriculture, Turkey) in this experiment (number of viable algae $2 \times 10^{7} \mathrm{alg} / \mathrm{ml} ; \mathrm{pH}: 7$; density: 1 ; content of amino acids and vitamins: arginine, cysteine, histidine, leucine, lysine, methionine, phenylanine, tryptophan, vailine, biotin, A, B1, B2, $\mathrm{C}, \mathrm{E})$. The application of foliar spray was generated the best method under the saline conditions (data not shown) in guar. The microbial fertilizer (MF) was sprayed on the foliage of plants to run off at three days apart.

Starting from 40 days of after sowing (DAS), watering and microalga treatments were applied. The experiment was consisted of 8 treatments: 1) control (S0: 100\% of field capacity), 
2) S1 (depletion of $75 \%$ the available water holding capacity), 3) S2 (depletion of $50 \%$ the available water holding capacity), 4) S3 (depletion of 25\% the available water holding capacity), 5) $\mathrm{S} 4$ (no applied irrigation water), $\mathrm{S} 1+\mathrm{MF}$ ( $\mathrm{S} 1+5 \%$ foliar microbial fertilizer treatment), 6) $\mathrm{S} 2+\mathrm{MF}, 7) \mathrm{S} 3+\mathrm{MF}, 8) \mathrm{S} 4+\mathrm{MF}$. The plants were subject to drought stress for 34 days.

The end of the experiment, plants were evaluated using some plant physiological (shoot fresh and dry weights, shoot length, shoot diameter, number of leaves per plant, leaf area per, relative water content, and biochemical parameters such as total phenolic content (TPC), lipid peroxide content (MDA); superoxide dismutase (SOD), catalase (CAT), ascorbat peroxidase (APX), and glutathione reductase (GR) antioxidative enzyme activities.

Relative water content (RWC\%) was estimated by following the method as prescribed by Turkan et al. [19]. The Folin-Ciocalteu reagent was used to determine the total phenolic content in the leaves and stems, which was given in milligrams. For the standard, gallic acid was used [20]. Flavonoid content was determined by colorimetric assay [21, 22]. The fresh weight (fw) total flavonoids was expressed as the milligram of quercetin equivalent in each gram.

A mortar and pestle were used to extract the enzymes from $0.5 \mathrm{~g}$ of leaf tissue, using $5 \mathrm{~mL}$ of extraction buffer [potassium-phosphate buffer $(50 \mathrm{mM})$ at $\mathrm{pH} 7.6$ and disodium ethylenediaminetetraacetate $(0.1 \mathrm{mM})]$. Centrifugation at $15,000 \times \mathrm{g}$ for $15 \mathrm{~min}$ was used for homogenization, and the resulting supernatant fraction was then used to assay for the enzymes. All of the enzyme extraction preparation operations were done at $4{ }^{\circ} \mathrm{C}$. The method of Karanlik [23] was used to assay the SOD, by observing the reduction of superoxide radical-induced nitro blue tetrazolium (NBT) at $560 \mathrm{~nm}$. Monitoring the disappearance of HO was used to determine the CAT activity, while measuring the ascorbate consumption (absorbance, $290 \mathrm{~nm}$ ) was used to determine the APX. One unit of APX activity was defined as the amount of enzyme required to consume $1 \mu$ mole of ascorbate $\min ^{-1}$ [24]. The Measuring the enzyme-dependent oxidation of NADPH (absorbance, $340 \mathrm{~nm}$ ) was used to determine the GR activity. The amount of enzyme that oxidized $1 \mu$ mole of NADPH $\min ^{-1}$ was used to define 1 unit of GR activity.

The amount of malondialdehyde (MDA) was determined by the thiobarbituric acid (TBA) reaction, which was then used to measure the lipid peroxidation [25]. The molar extinction coefficient of the MDA $\left(155 \mathrm{mM}^{-1} \mathrm{~cm}^{-1}\right)$ was used to calculate the MDA content.

A completely randomized plot design was used for the experiment, with 3 replicates. The least significant difference (LSD) test was used to compare the mean values of the parameters. Statistical significance was accepted as $p<0.05$ via JUMP 5.1. Data are shown as the mean \pm standard deviation $(\mathrm{Sd})$ and in all figures error bars are representing standard errors of the means.

\section{Results}

Drought stress markedly reduced growth parameters such as shoot fresh and dry weight, shoot length, shoot diameter, number of leaves and brunch per plant, leaf area per plant, root fresh and dry weights (Fig. 1). These traits were decreased different levels in drought stresses compared to the control. The highest decrease was determined in S4 treatment (average 77.8\% decrease). The fresh and dry weight was decreased by 24 and $31 \%$ under S1 and S2, respectively. However these decreases reached 71 and $82 \%$ in S3 and S4 conditions compared with control groups. Drought stress had adverse effects, not only on seedling biomass, but also on other morphological parameters such as shoot diameter, number of leaves and brunch per plant, leaf area per plant, root fresh and dry weights while S3 and S4 drought conditions caused significant reductions $(\mathrm{p} \leq 0.05)$ in these descriptions. While the reductions under S1 and S2 drought conditions decreased by 18 and $38 \%$, under S3 and S4 stress conditions decreased by 55 and $76 \%$, respectively. However, MF application under drought stress significantly enhanced growth components compared to those drought stressed groups. In S1+MF and S2+MF treatments, growth parameters increased 3-14\% compared to control treatment. In addition, When MF application compared to S groups; MF enhanced to amelioration for growth by $5-1178 \%$. 

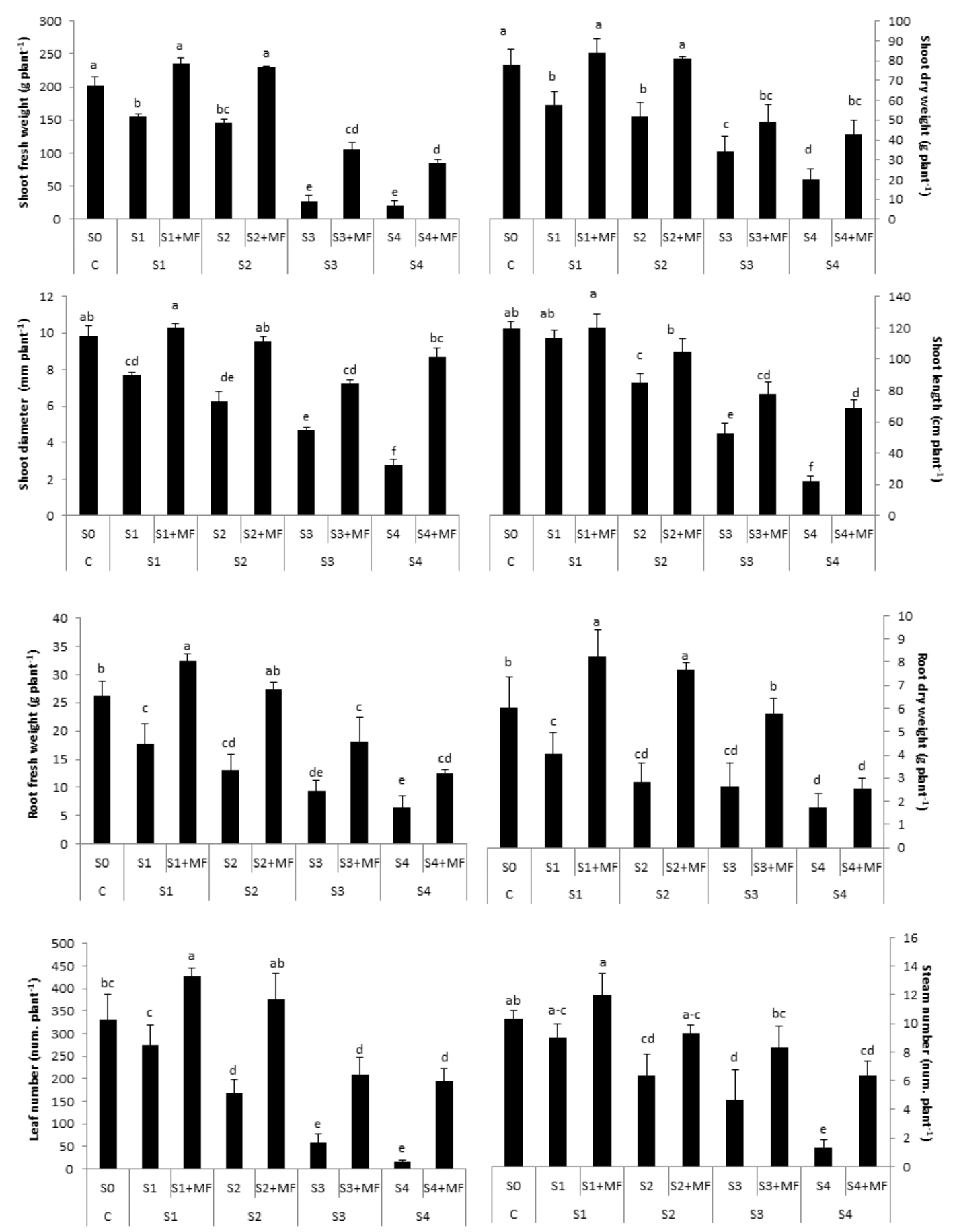

Figure 1. Effects of MF application on growth parameters of guar under drought condition. Each value represents the mean of three replicates. For each parameter of each different letters are significantly different at $\mathrm{p} \leq 0.05$ according to Student's $\mathrm{t}$ test

Guar seedlings treated with different levels (S1, S2, S3, and S4) drought stress showed decreased RWC at 7.20, 14.40, 27.70, and 39.57\% as compared to control (Fig. 2). However, a significant improvement in the RWC of MF treated plants was observed increasing by 3.10, 6.73, 5.97, and $16.7 \%$ when compared with the plant treated with non -MF drought stresses $(\mathrm{p} \leq 0.05)$. 

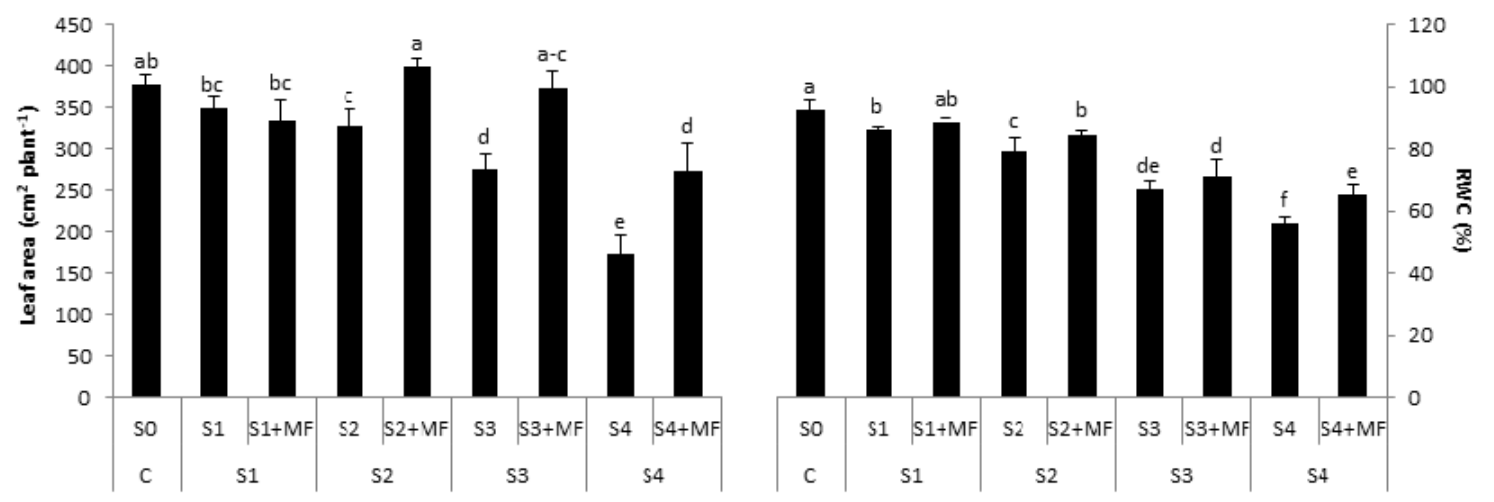

Figure 2. Effects of MF application on leaf area and RWC of guar under drought condition. Each value represents the mean of three replicates. For each parameter of each different letters are significantly different at $\mathrm{p} \leq 0.05$ according to Student's t test

To confirm the drought induced oxidative stress conditions, intercellular levels of stress biomarker MDA was evaluated (Fig. 3). The MDA content was the lowest in control plants $\left(2.40 \mu \mathrm{mol} \mathrm{g}^{-1} \mathrm{FW}\right)$ and increased significantly under drought conditions. When compared with the control groups, the highest MDA level was determined S4 treatment in guar plants $\left(20.22 \mu \mathrm{mol} \mathrm{g}^{-1}\right.$ FW). But, MF mitigated the stress effects on plants and further decreased the contents of MDA. In point of fact, through MF treatment, MDA content was decreased at average $25.83 \%$ rations.

Under drought stress, total phenolic and flavonoid contents decreased in guar (3-39\% decreases) compared to control (Fig. 3). Contrary, MF treatment proved to result in significant increase in the mean values of total phenolic and flavonoid contents compared with individually drought stress (24-48\% increase).
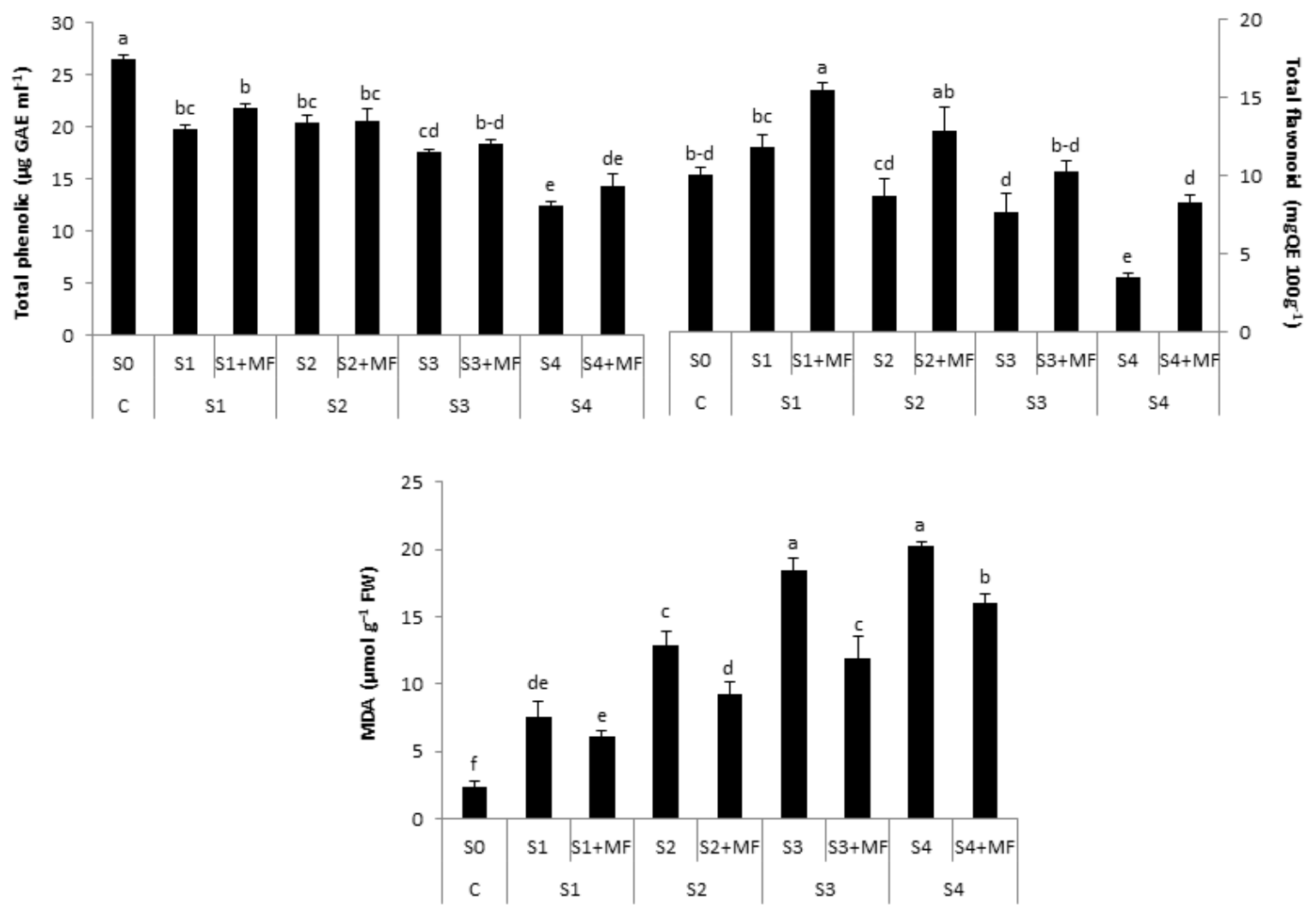

Figure 3. Effects of MF application on total phenolic, flavonoid, and MDA contents of guar under drought condition. Each value represents the mean of three replicates. For each parameter of each different letters are significantly different at $p \leq 0.05$ according to Student's $t$ test 
Antioxidative enzyme activity (SOD, CAT, APX and GR) levels were evaluated in control, drought levels (S1, S2, S3, and S4), and drought with MF treatments (Fig. 4). Drought stress caused increase SOD, CAT, APX and GR activities different levels. Under non MF experiments, the highest SOD and GR activity was determined as $423.26 \mathrm{U} \mathrm{min}^{-1} \mathrm{mg}^{-1} \mathrm{FW}$ and $38.63 \mu \mathrm{mol} \mathrm{min}^{-1}$ $\mathrm{mg}^{-1} \mathrm{FW}$ in S2 (415.79 and 32.20\% increase vs control, respectively). On the other hands, CAT activity with $113 \%$ increase, reached $3087.99 \mu \mathrm{mol} \mathrm{min}^{-1} \mathrm{mg}^{-1} \mathrm{FW}$ under S3 treatment. It is evident from Figure 1 that MF treatments had a serious effect on antioxidative enzyme activities such as SOD, CAT, APX, and GR of the guar plants under all drought treatments. At MF application, these enzyme activities increased by 403.39, 193.28, 57.18, and $35.70 \%$ in comparison with control treatment. When these parameters comparison non- MF treatment drought conditions, increase was determined by $17.13,76.25,9.91$, and $20.76 \%$.
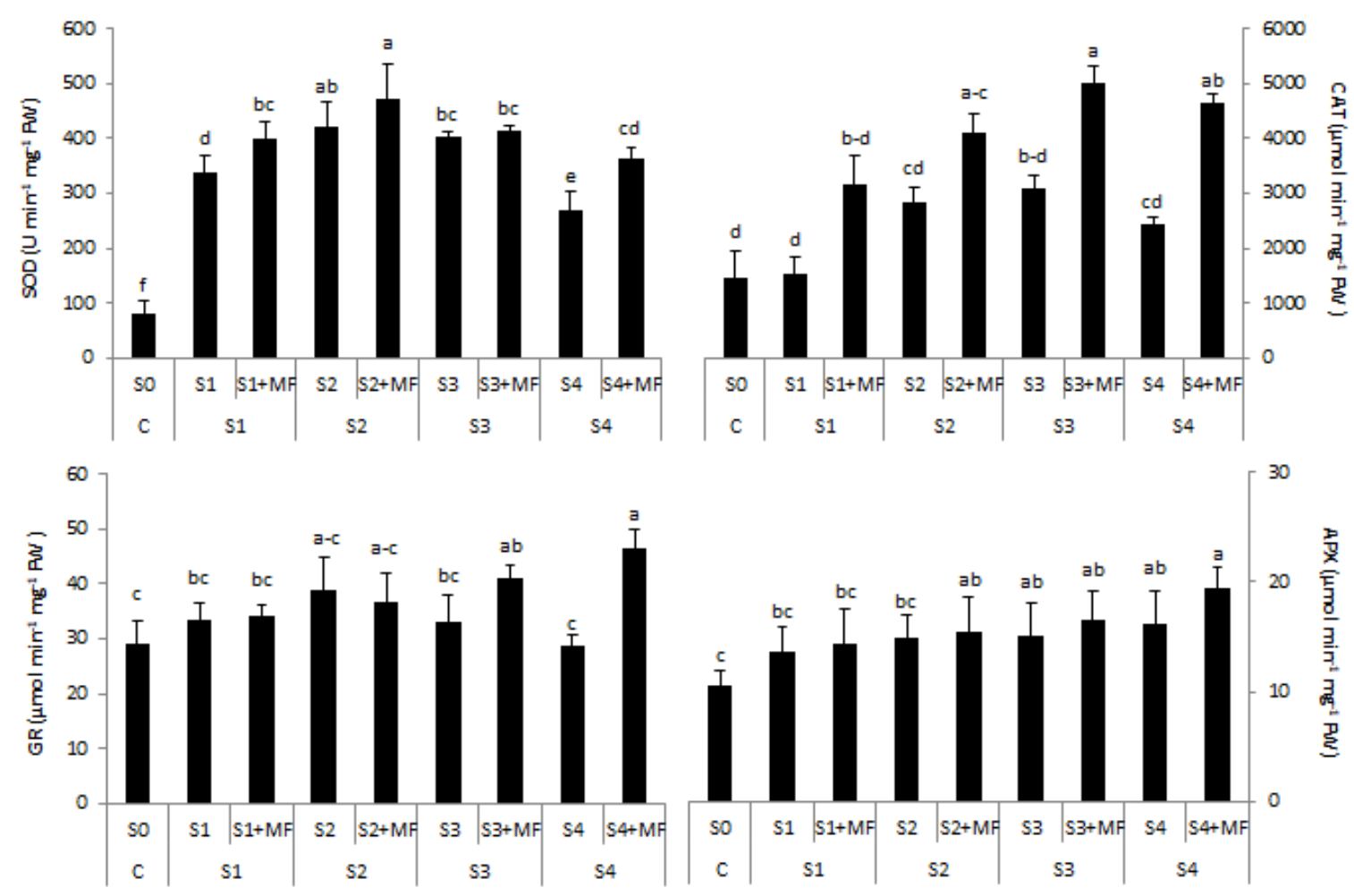

Figure 4. Effects of MF application on SOD, CAT, GR, and APX enzyme activities of guar under drought condition. Each value represents the mean of three replicates. For each parameter of each different letters are significantly different at $\mathrm{p} \leq 0.05$ according to Student's $t$ test

\section{Discussion}

Drought has detrimental affects plant growth and development, and substantially reduces biomass accumulation and crop growth rates. In crop plants, drought results in severe consequences such as a reduction in the cell division and expansion rates and size of the leaves, elongation of the stem and proliferation of the root, and a disturbance in stomatal oscillations, plant water/nutrient relations and lower productivity, and water use efficiency (WUE) [26]. The genetic connections of several water-stressed guar genotype seedling traits were assessed by Bibi et al. [27], who found an important relationship between the length of the shoot, chlorophyll $\mathrm{a} / \mathrm{b}$, and fresh and dry weight of the shoot (with irrigation), which suggested that selecting drought-resistant genotypes could help to improve yield when plants are under water-stress conditions. Chlorella vulgaris, the green algae, is a photosynthetic organism that is regarded as a crucial biofertilizer. It has mainly been studied because it is commercially significant due to its high protein levels, vitamins, essential amino acids, and fatty acids [28]. It has been shown; microbial fertilizer (MF) application was successful in limiting the effects of drought on the growth of guar seedlings and development in this study. The 
favorable effect of microalgae might be predicated to its success providing the plants with necessary nutrients and phytohormones. Tarraf et al. [29] showed that fenugreek plants treated with a foliar application of algae extract had a significantly increased the number of leaves and branches, plant height, and fresh and dry weight during the vegetative growth and flowering stages. Sharara and ElAal [30] reported that microbial inoculation such as microalgae stimulated growth in the plants in 2 ways: 1) directly, through the production of plant hormones and an improved uptake of nutrients, or 2) indirectly, via microbial balance changes in the rhizosphere towards beneficial micro-organisms. Using of Chlorella vulgaris based microbial fertilizer (MF) with drought stress could be enhancing the nutrient uptake of plant which means the status may be help amelioration at growth parameters. Thus, compared to control condition, growth parameters decreased by $24-82 \%$; however, when microalgae were applied, these impulses were determined by $18-76 \%$ rations. In fact, this hypothesis were reported that in corn [31, 32], wheat, bean and lettuce [33]. In addition to this, the growth medium and cellular extracts of some species of microalgae have been reported as containing phytohormones (auxins, abscisic acid, cytokinins, gibberellins, and salicylic acid), all of which play a significant role in the development of plants. Plant hormones are vital for a variety of plant development and growth aspects. Cell division, the regulation of root and shoot development, stimulation of leaf growth, and formation of flowers, fruit, and seeds are the result of cytokinins, as a result of their stabilizing effect on photosynthetic machinery, ability to suppress senescence, and improve sink strength and nitrogen acquisition [10]. Such as other growth parameters, steam number, leaf number and area decreased at drought treatments 48,60 , and 25\%, respectively. With application of Chlorella vulgaris based microbial fertilizer (MF), protection of loss at steam number, leaf number and area values showed increasing 133, 401, and 27\% under drought stresses, respectively. This situation may be the result of an increased access to nutrients responsible for augmenting protein synthesis, leading to an increased accumulation of carbohydrate by means of Chlorella vulgaris [28].

The leaf relative water content, net photosynthetic rate, shoot water potential, starch and soluble proteins, total chlorophyll, and nitrate reductase activity at different stages of growth are significantly decreased [34]. Under an irrigation deficit caused to plants display mild dehydration, which is seen through decreased water capacity, due to greater water uptake difficulties or a lower substrate water level. The most negative leaf water and stem water potential values were observed in water-stressed plants [35]. Nxele et al. [36] reported that one of the most effortless agricultural variables used for screening plants for a tolerance to drought is the relative water content. While RWC values decreased under drought stress average $22 \%$, with microalgae application RWC has shown increase $8.1 \%$ in the same conditions. Increased leaf RWC by microalgae under drought stress suggests that microalgae application could enhance leaf guar water relations and support maintaining cell turgor pressure.

The extent of damage in stressed plants is reflected in changes in the permeability of the cell membrane [37]. Free radical formation in plants is the result of drought stress, which causes irreversible lipid and protein damage. The accumulation of MDA was determined in the guar plant leaves under various conditions (Fig. 3), and a significant MDA increase (the highest level) was observed under water stress (18.41 and $20.22 \mu \mathrm{mol} \mathrm{g}^{-1} \mathrm{FW}$ ) under S3 and S4 treatments, respectively. This chance was more clearly observed due to the $742 \%$ increase in S4 when compared to the control plants. Drought stress in plants results in free radical formation, which causes damage that, is irreversible in proteins and lipids. Cell membrane integrity is destroyed by lipid peroxidation, which, over time, results in cell death [38]. The lipid peroxidation increase is due to compounds such as superoxide radicals $\left(\mathrm{O}_{2}{ }^{-}\right)$, hydrogen peroxide $\left(\mathrm{H}_{2} \mathrm{O}_{2}\right)$, and hydroxyl radicals $(\mathrm{OH})$ in chloroplasts. According to Guo et al. [37] a significant result of membrane lipid peroxidation is strongly-cytotoxic MDA. The amount of plant damage is positively related to the accumulation of MDA under stress, and is negatively correlated with resistance to drought. In this study, lipid peroxidation increased with drought stress. In previous studies [39-41], MDA levels were observed to increase, in relation to the formation of ROS, in phenotypes that were susceptible to drought stress. Such results may have been the result of varieties with the ability to genotypically 
scavenge ROS and/or protect itself against ROS oxidative properties. In this study, the results showed that Chlorella vulgaris based microbial fertilizer (MF) treatment reduced the MDA levels by $19-35 \%$ rations, presenting a favorable effect in reducing the oxidative stress resulting from drought stress.

During extreme environmental conditions, microalgae multiply due to stress and a variety of secondary metabolites are synthesized and produced, which is assumed to be an endeavor by microorganisms at retaining their rate of growth or increasing their likelihood of survival [42]. Our results indicated that usage of MF maintained an important increase in total phenolic and flavonoid contents compared to untreated plants under drought stress (60.70 and $174.80 \%$ increase). These results clearly indicate that the Chlorella vulgaris based microbial fertilizer (MF) plays a stimulatory role in phenolic accumulation in guar. Similarly, Abd El-Baky et al. [43] reported that microalga is a source of unique compounds that are biologically active, like phenols, polysaccharides, phycobiline, steroids, and terpenoids. The elevated total phenol level is believed to be a result of significant photosynthesis rates, which is predicated by a large photosynthetic area and high photosynthetic pigment levels using a treatment of yeast as a biofertilizer [28].

Drought stress normally results in oxidative stress caused by stomatal closure, which brings about the over-reduction of the photosynthetic electron transport chain (ETC) and overproduction of ROS, which results in an increase of oxidative stress [37]. An increase in oxidative stress and the highly-toxic over-production of ROS, which results in DNA, protein, lipid, and carbohydrate damage, has been observed in plants exposed to most types of abiotic stress [23]. Straight a consequence of stress is the induction of stress antioxidant enzymes by exposed plants to minimize damage caused by reactive oxygen species [44]. Enzymatic antioxidant defense systems, such as APX, CAT, DHAR, GR, MDHAR, POX, SOD and non-enzymatic antioxidant defense systems, like ascorbate, carotenoids, glutathione, glycine betain, phenolic compounds, polyamines, proline, and sugar $[40,45]$. The most of results indicated that due to drought stress, APX, CAT, and SOD activities are positively related to drought tolerance $[37,40,44]$. Superoxide dismutase (SOD) is a significant enzyme in the water cycle; that is able to convert $\mathrm{O}_{2}^{-}$into $\mathrm{H}_{2} \mathrm{O}_{2}$ and $\mathrm{O}_{2}$, and plays a vital role in defending against superoxide-derived oxidative stress in plant cells. Hydroxyl $(\mathrm{OH})$, which is a highly-reactive extremely toxic oxide, indiscriminately reacts with all macromolecules. A combination of the SOD and CAT actions is able to decrease or prevent hydroxyl formation [40]. Our results showed that both genotypes induced SOD and CAT activities upon drought, consistent with the increment in peroxidation levels. When exposed to drought stress, SOD and CAT activity showed increase with drought level. However, these increase was limited S4 level. Compared to control conditions, SOD and CAT activities increased by 336.75 and $71.26 \%$ when with MF application, these increases were determined as 403.39 and $193.28 \%$, respectively. $\mathrm{H}_{2} \mathrm{O}_{2}$ is reduced into water by ascorbate peroxidase (APX), using ascorbic acid (AsA) as a distinct electron donor, in chloroplasts, which is the most significant peroxidase in plants for the detoxification of $\mathrm{H}_{2} \mathrm{O}_{2}$ [37]. Under stress, GR sustains the cytoplasm's GSSG to GSH pool, preserving the balance of redox in the cells via the inter-conversion of the reduced GSH and oxidized GSSG that was catalyzed by the GR. All of these act to correctly scavenge ROS that are toxic and protect the plants against damage from ROS [37]. The results showed that APX and GR activities increased under stress conditions compared to the control and these rations were determined to be 42.60 and $14.58 \%$, respectively, in only drought treatment. In here, in which response to microalgae application in drought-stressed medium were examined, researchers reported increased APX and GR enzyme activities were statistically significant and determined by 57.18 and $35.70 \%$ rations. Singh et al. [11] reported that plants have defenses against oxidative damage including physiological and biochemical status changes using PGPRs to facilitate protection against losses due to pathogens or abiotic stress, and improved plant tolerance to abiotic stress as a result of physical and chemical changes is an approach that is rather new and overlaps a great deal with the process of systemically-induced resistance in plants. Since microalgae Chlorella vulgaris a colonial green microalga [11], it might be assists plants in plants to nurture growth under drought stress due to the evocation of the generated systemic responses in plants as PGPR. 


\section{Conclusion}

From the observations of physiological and biochemical analyses, we found that Cyamopsis tetragonoloba (L.) Taub. plants could enhance their ability by up-regulating antioxidative systems and making osmotic adjustments in response to drought stress. It is possible that proline, secondary metabolite accumulation and antioxidative enzyme activities could be used as effective mechanisms for drought tolerance. Microbiological fertilizers are important to environment favorable and renewable cheaper source for agricultural practices. One of the most significant features that make microalgae valuable; contain a high macronutrient content, and substantial amino acid and micronutrient content. The application of Chlorella vulgaris based microbial fertilizer to drought seemed favorable to development and growth and the biochemical and physiological processes of the guar. Therefore, microalgae application has been achieved to be helpful strategy for enhancing the tolerance of the guar plants when grown under drought conditions.

\section{Conflict of Interest}

The author(s) declare(s) that there is no conflict of interest.

\section{Author Contributions}

Conceived and designed the experiments AK and SK. Performed the experiments: AK and SK. Analyzed the data: SK. Contributed reagents/materials/analysis tools: AK and SK. Wrote the paper: SK. Revised the paper: AK. All authors read and approved the final manuscript.

\section{References}

[1] S.I. Zandalinas et al., Plant adaptations to the combination of drought and high temperatures, Physiologia plantarum. 162 (2018) 2-12.

[2] K. Shinozaki et al., Molecular responses to drought stress in plant regulation of gene expression and signal transduction, Plant Responses to Environmental Stress. 17 (1999) 133-143.

[3] Y. Fang, L. Xiong, General mechanisms of drought response and their application in drought resistance improvement in plants, Cellular and molecular life sciences. 72 (2015) 673-689.

[4] J. Li et al., Exogenous melatonin alleviates damage from drought stress in Brassica napus L. (rapeseed) seedlings, Acta Physiologiae Plantarum. 40 (2018) 43.

[5] J. Singh, J.K. Thakur, Photosynthesis and Abiotic Stress in Plants, in: Biotic and Abiotic Stress Tolerance in Plants Springer, Singapore, 2018, pp. 27-46.

[6] S. Kumar et al., Plant Responses to Drought Stress: Physiological, Biochemical and Molecular Basis, in Biotic and Abiotic Stress Tolerance in Plants, Springer, Singapore, 2018, pp. 1-25.

[7] J.K. Vessey, Plant growth promoting Rhizobacteria as bio-fertilizers, Journal of Plant and Soil. $225(2003) 571-86$.

[8] I. Ju et al., A review: Biofertilizer-A key player in enhancing soil fertility and crop productivity, Journal of Microbiology and Biotechnology Reports, 2 (2018).

[9] L. Jian, Advance in role mechanism of microbial fertilizer. Journal of Microbiology, 1 (2001).

[10]B.M. Plaza et al., Effect of microalgae hydrolysate foliar application (Arthrospira platensis and Scenedesmus sp.) on Petunia x hybrida growth, Journal of Applied Phycology. 2018 1-7.

[11]R. Singh et al., Sodium chloride incites reactive oxygen species in green algae chlorococcum humicola and chlorella vulgaris: implication on lipid synthesis, mineral nutrients and antioxidant system, Bioresource Technology. 270 (2018) 489-497.

[12]H. Righini, R. Roberti, E. Baraldi, Use of algae in strawberry management, Journal of Applied Phycology. 2018 1-14.

[13]H. Elarroussia et al., Microalgae polysaccharides a promising plant growth biostimulant, Journal of Algal Biomass Utilization. 7 (2016) 55-63. 
[14] V. Barone et al., Root morphological and molecular responses induced by microalgae extracts in sugar beet (Beta vulgaris L.), Journal of Applied Phycology. 30 (2018) 1061-1071.

[15]M. Kumar et al., Performance of cultivar and irrigation scheduling (IW: CPE ratio) on yield, water use efficiency, consumptive use of water and economics of summer clusterbean (Cyamopsis tetragonoloba L.) under middle Gujarat conditions, Res. Env. Life Sci. 8 (2015) 599-602.

[16]D.M. Mac, M.F.E.M Ahmed, S.A. Binyason, Effect of water stress at different periods on vegetatıve growth of guar grown under irrigation conditions, International Journal of Applied Biology and Pharmaceutical Technology. 7 (2016) 1-6.

[17] S.P. Vyas et al., Influence of potassium on water relations, photosynthesis, nitrogen metabolism and yield of clusterbean under soil moisture stress, Indian Journal of Plant Physiology. 6 (2001) 30-37.

[18]H.Y. Dasgan, S. Koc, Evaluation of salt tolerance in common bean genotypes by ion regulation and searching for screening parameters, Journal of Food, Agriculture Environment. 7 (2009) 363-372.

[19]I. Turkan et al., Differential responses of lipid peroxidation and antioxidants in the leaves of drought-tolerant $P$. acutifolius Gray and drought-sensitive $P$. vulgaris L. subjected to polyethylene glycol mediated water stress, Plant Science. 168 (2005) 223-231.

[20] V.L. Singleton, R. Orthofer, R.M Lamuela-Raventós, Analysis of total phenols and other oxidation substrates and antioxidants by means of folin-ciocalteu reagent, In Methods in Enzymolog. 299 (1999) 152-178.

[21]D.M.A. Molina-Quijada et al, Phenolic compounds and antioxidant activity of table grape (Vitis vinifera L.) skin from northwest Mexico, CyTA-Journal of Food, 8 (2010) 57-63.

[22] L.A. Medina-Juárez et al., Antioxidant activity of peppers (Capsicum annuum L.) extracts and characterization of their phenolic constituents, Interciencia. 37 (2012) 588-592.

[23] S. Karanlik, Resistance to salinity in different wheat genotypes and physiological mechanisms involved in salt resistance, M.S. thesis, Institute of Natural and Applied Sciences, University of Cukurova, Turkey, 2001.

[24]I. Cakmak, H. Marschner, Magnesium deficiency and highlight intensity enhance activities of superoxide dismutase, ascorbate peroxidase and glutathione reductase in bean leaves, Plant Physiology. 98 (1992) 1222-1226.

[25]Heath, R.L., Packer, L. (1968). Photoperoxidation in isolated chloroplasts. I. Kinetics and stoichiometry of fatty acid peroxidation. Arch. Biochem. Biophys, 125: 189-198.

[26]M. Farooq et al., Drought stress in plants: an overview, in Plant responses to drought stress, Springer, Berlin, Heidelberg, 2012, 1-33.

[27]A. Bibi et al., Assessment of genetic association among seedling traits in guar (Cyamopsis tetragonoloba L.) genotypes under water stress conditions, Int J Res Stud Biosci. 2 (2014) 2029.

[28]R. Dineshkumar et al., Exploring the microalgae biofertilizer effect on onion cultivation by field experiment, Waste and Biomass Valorization. 2018 1-11.

[29] S.A. Tarraf et al., Influence of foliar application of algae extract and amino acids mixture on fenugreek plants in sandy and clay soils, Amino Acids. 16 (2015) 19-58.

[30]M. S. Sharara, H.A.A El-Aal, Effect of some bio-fertilizers on growth, productivity, chemical composition and processing of cassava tubers, Alexandria Journal of Agricultural Sciences. 61 (2016) 529-539.

[31]M. Grzesik, Z. Romanowska-Duda, Improvements in germination, growth, and metabolic activity of corn seedlings by grain conditioning and root application with cyanobacteria and microalgae, Polish Journal of Environmental Studies. 23 (2014) 1147-1153.

[32]T.M. Taha, M.A. Youssef, Improvement of growth parameters of Zea mays and properties of soil inoculated with two Chlorella species, Rep Opin. 7 (2015) 22-27. 
[33] T.I. Hajnal-Jafari, S.S. Đurić, D.R. Stamenov, Influence of green algae Chlorella vulgaris on initial growth of different agricultural crops, Matica Srpska Journal for Natural Sciences. 130 (2016) 29-33.

[34]R. Pathak, Clusterbean: Physiology, Genetics and Cultivation. Springer, 2015.

[35]J. R. Acosta-Motos et al., Plant responses to salt stress: adaptive mechanisms, Agronomy. 7 (2017) 18.

[36]X. Nxele, A. Klein, B.K. Ndimba, Drought and salinity stress alters ROS accumulation, water retention, and osmolyte content in sorghum plants, South African Journal of Botany. 108 (2017) 261-266.

[37] Y.Y. Guo et al., Energy dissipation and antioxidant enzyme system protect photosystem II of sweet sorghum under drought stress, Photosynthetica. 2018 1-12.

[38] A. Dolatabadian, S.A.M.M. Sanavy, N.A. Chashmi, The effects of application of ascorbic acid (Vitamin C) on antioxidant enzymes activites, lipid peroxidant and proline accumulation of canola (Brassica napus L.) under conditions of salt stress, J. Agronomy and Crop Science. 194 (2008) 206-213.

[39]M.A. Rosales et al., Physiological analysis of common bean (Phaseolus vulgaris L.) cultivars uncovers characteristics related to terminal drought resistance, Plant physiology and biochemistry. 56 (2012) 24-34.

[40]S. Kusvuran, H.Y. Dasgan, Drought induced physiological and biochemical responses in Solanum lycopersicum genotypes differing to tolerance, Acta Sci. Pol. Hortorum Cultus. 16 (2017) 19-27.

[41]H.K. Soureshjani et al., Responses of two common bean (Phaseolus vulgaris L.) genotypes to deficit irrigation, Agricultural Water Management. 213 (2019) 270-279.

[42] G. Markou, E. Nerantzis, Microalgae for high-value compounds and biofuels production: a review with focus on cultivation under stress conditions, Biotechnology Advances. 31 (2013) 1532-1542.

[43]H.H. Abd El-Baky, F.K. El Baz, G.S. El-Baroty, Production of phenolic compounds from spirulina maxima microalgae and its protective effects in vitro toward hepatotoxicity model, Electronic Journal of Environmental, Agricultural \& Food Chemistry. 8 (2009) 1099-1112.

[44]T. Amar, Y. Nourredine, Morphometric variability and biochemical analysis of growth seedlings under salt stress in tomato (Lycopersicon esculentum Mill.) cultivar, Molecular Plant Breeding. 7 (2016) 1-9.

[45]A. Sen, Oxidative stress studies in plant tissue culture, Antioxidant Enzyme. 3 (2012) 59-88. 